\title{
Screening for visual defects in preschoolchildren
}

\author{
R M INGRAM, W W HOLLAND, * C WALKER, J M WILSON. P E ARNOLD, \\ AND S DALLY
}

From Kettering and District General Hospital, Kettering, Northamptonshire

SUMmaRY There is no evidence to support the suggestion that a widespread programme of vision screening at age $3 \frac{1}{2} 2$ should be instituted. Some of the practical problems and defects of such a programme are outlined. If the issues raised are to be resolved by further research, identification of preschoolchildren who have visual problems will be facilitated by a screening procedure involving refraction and possibly a cover test.

In 1976 the Court Report' recommended that children should have their vision screened at the age of $3 \frac{1}{2}$ years. Screening at this age is supported on the grounds that squint and amblyopia would be identified at an age when remedial treatment might be successful. However, although a number of trials of screening children at this age have been conducted over the past 20 years, ${ }^{2}$ screening has never been continued long enough for a full evaluation. The two most recent reports on this subject ${ }^{34}$ have not produced convincing evidence in favour of vision screening at this age.

While it is important that new advances should be introduced into medical practice, it would be wrong to adopt a procedure before it had been adequately evaluated. Sackett and Holland ${ }^{5}$ have pointed out that 'implementation of untested community screening or treatment renders their subsequent evaluation more difficult and less decisive . . . indeed it may become impossible to correct the original error.' As has been found for screening and treatment for cervical cancer, once a procedure has been introduced and accepted by both clinicians and the public, it is extremely difficult then to withdraw that service or even to subject it to a randomised controlled trial. Such a trial, therefore, should be carried out before a new screening procedure is introduced.

The investigation reported here, conducted in a circumscribed area of Northamptonshire, attempts to determine to what extent screening of $31 / 2$-year-old children for visual defects would satisfy the criteria outlined by Wilson and Jungner. ${ }^{6}$ It represents a preliminary report of the findings of six years of

Correspondence to Dr R M Ingram, Kettering and District General Hospital, Rothwell Road, Kettering, Northants NN16 8UZ.

* St Thomas's Hospital, London. screening children at this age and deals with the methods that are available to do this, the visual defects found, and with the follow-up and treatment offered on the detection of a possible defect. The children screened were born between January 1973 and December 1978, and conclusive information on the vision of some of the younger ones may yet present itself.

Earlier investigations were confirmed to assessment of visual acuity at the age of $31 / 2{ }^{2}$ Two other methods have since been suggested: (1) a subjective test for stereoacuity ${ }^{7} ;$ (2) an objective search for abnormal refractions. ${ }^{8}$ The use of all three methods of identifying 'abnormal vision' is compared here.

For the purpose of this article 'abnormal vision' means squint and/or defective visual acuity. The heading 'defective visual acuity' includes both blurred vision correctable by spectacles alone and amblyopia. In our experience it has not been easy to differentiate between these two conditions in a preschool child. Although ophthalmologists and others profess to be primarily interested in early identification and treatment of amblyopia, defective visual acuity correctable by spectacles alone is just as important.

\section{Patients and methods}

SAMPLE

All children who were on the lists of three general medical practices in the towns of Rushden and Higham Ferrers were sent appointments for vision screening during the month they attained the age of $31 / 2$ years. Names were obtained from the health visitor's records and practice age/sex registers. The children were born between 1 January 1973 and 31 December 1978. Most of those born in the years 
1975-8 had also previously been sent appointments for vision screening at 1 year of age, and these particular children form the basis of an adjacent paper' ${ }^{9}$ reporting the ability to predict amblyopia at age 1 year.

Those who did not attend for screening at $31 / 2$ were not sent a second appointment, but hospital records were searched to see if they had previously been identified as having a visual problem. A record was also kept of children seen after the age of $3 \frac{1}{1 / 2}$. This includes two groups of children: those who were thought to be normal at $3 \frac{1}{2}$ but who were subsequently found to have abnormal vision; and those who did not attend at $3 \frac{1}{2}$, some of whom were living in the district but were not known to the authorities.

The follow-up period varied, with those born in December 1978 being followed up to 5 years of age and those born in January 1973 to 11 years of age.

\section{METHODS OF VISION SCREENING}

All the children were seen first by an orthoptist, who: (1) performed the cover test; (2) recorded visual acuity using only the Linear Sheridan-Gardiner or Snellen test at 6 metres; and (3) recorded stereoacuity using the Reinecke $E$ test, but this was later abandoned. Cyclopentolate $1 \%$ drops were then instilled into both eyes, and $\mathbf{3 0}$ minutes later retinoscopy was performed, in all cases by the same ophthalmologist.

If a child did not have normal visual acuity or had a squint, the orthoptist gave the mother a note stating the defect found and instructed her not to show it to the ophthalmologist until he asked for it after retinoscopy had been performed. Thus clinical examination was performed in ignorance of the retinoscopy findings, and retinoscopy was carried out without prior knowledge of the visual acuity.

Vision was deemed to be abnormal if there was a squint and/or, at the time of screening, defective acuity without optical correction. Criteria for defec- tive acuity were vision of $6 / 12$ partly or less in either eye and/or a difference of more than one line between the acuities of a pair of eyes even if the acuity was better than $6 / 12$. If acuity was defective and the cycloplegic refraction was 'normal' (see below), acuity was reassessed three to six months later without any treatment. Spectacles were prescribed if the refraction and vision were both 'abnormal' at the time of the first test.

A refraction (after $1 \%$ cyclopentolate) was considered to be abnormal if one or more of the following features were present: (1) bilateral spherical hypermetropia of $+2.00 \mathrm{D}$ sphere or more; (2) myopia; (3) astigmatism of 1.5 dioptres (myopic, hypermetropic or mixed), present in either or both eyes; (4) the refraction of one of a pair of eyes differed from its fellow by 1.00 or more $D$ sphere and/or cyl.

\section{Results}

1507 children born during the years $1973-8$ attended for vision screening as they reached the age of $3 \frac{1}{2}$. This represented a mean attendance rate of $72 \cdot 3 \%$ of the target population and for individual years varied from $70 \cdot 4 \%$ to $75 \cdot 4 \%$.

In the first year of the study 268 children were screened. It took an average of $4 \cdot 1$ minutes to assess the visual acuity of both eyes of a child, with a range of 2-11 minutes. The stereoacuity test took on average 1.6 minutes, with a range of 1-4 minutes. Retinoscopy was not timed, but since most children are emmetropic or nearly so it would on average have taken less than 1 minute per child.

Visual defects identified at the time of screening at $31 / 2$ years are only a proportion of the total since (Table 1): (1) $26 \%$ of those with abnormal vision had presented before $3 \frac{1}{2} 2$ years (col. 3); (2) $40.9 \%$ were identified at $3 \frac{1}{2}$ years screening (col. 4); (3) $33 \%$ presented after $3 \frac{1}{2}$ years (cols. 5 and 6 ). Of the latter

Table 1 Summary of when children presented with abnormal vision

\begin{tabular}{|c|c|c|c|c|c|c|c|}
\hline \multirow[b]{2}{*}{ Year of birth } & \multirow[b]{2}{*}{$\begin{array}{l}\text { (1) } \\
\text { Population* }\end{array}$} & \multirow[b]{2}{*}{$\begin{array}{l}\text { Total with } \\
\text { abnormal vision }\end{array}$} & \multirow[b]{2}{*}{$\begin{array}{l}\% \text { of } \\
\text { population }\end{array}$} & \multicolumn{4}{|c|}{ Number (and percentage) with abnormal vision } \\
\hline & & & & $\begin{array}{l}\text { (3) } \\
\text { Presented } \\
\text { before } 31 / 2(\%)\end{array}$ & $\begin{array}{l}\text { (4) } \\
\text { Detected } \\
\text { at } 31 / 2+(\%)\end{array}$ & $\begin{array}{l}\text { (5) } \\
\text { False/normal } \\
\text { at } 31 / 2(\%)\end{array}$ & $\begin{array}{l}(6) \\
\text { Not seen } 31 / 2 \\
\text { presented later }(\%)\end{array}$ \\
\hline 1973 & 392 & 32 & $8 \cdot 2$ & $7(21 \cdot 9)$ & $14(43 \cdot 4)$ & $3(9.4)$ & $8(25 \cdot 0)$ \\
\hline 1974 & 389 & 29 & $7 \cdot 5$ & $8(27 \cdot 6)$ & $6(20 \cdot 7)$ & $7(24 \cdot 1)$ & $8(27 \cdot 6)$ \\
\hline 1975 & 359 & 31 & $8 \cdot 6$ & $9(29 \cdot 0)$ & $12(38 \cdot 7)$ & $3(9.7)$ & $7(22 \cdot 6)$ \\
\hline 1976 & 415 & 28 & $6 \cdot 7$ & $8(28 \cdot 6)$ & $11(39 \cdot 3)$ & $3(10 \cdot 7)$ & $6(21 \cdot 4)$ \\
\hline 1977 & 351 & 31 & $8 \cdot 8$ & $5(16 \cdot 1)$ & $17(54 \cdot 8)$ & $5(16 \cdot 1)$ & $4(12.9)$ \\
\hline 1978 & 364 & 30 & $8 \cdot 2$ & $10(33 \cdot 3)$ & $14(46 \cdot 7)$ & $5(16 \cdot 7)$ & $1(3 \cdot 33)$ \\
\hline Total & 2270 & $181 \ddagger$ & $8 \cdot 0$ & $47(26 \cdot 0)$ & $74(40.9) \S$ & $26(14 \cdot 4)$ & $34(18 \cdot 8)$ \\
\hline
\end{tabular}

*All eligible children including non-attenders for screening at $31 / 2$ years at $31 / 2$ years $\ddagger$ Includes 13 myopes \$Includes 11 myopes

†Includes those where diagnosis of abnormal vision was uncertain 
Table 2 Comparison of results of screening at $31 / 2$ years with last known vision status*

A. Screening by assessment of visual acuity and/or presence of squint Last known vision

\begin{tabular}{lccr} 
& Normal & Abnormal & Total \\
\hline Normal & & & \\
Abnormal & 1310 & 26 & 1336 \\
Uncertain & 60 & 61 & 91 \\
Total & 67 & 13 & 80 \\
& 1407 & 100 & 1507 \\
\hline
\end{tabular}

B. Refraction of children whose vision was uncertain at $31 / 2$ Last known vision

\begin{tabular}{lcc}
\cline { 2 - 3 } Refraction at $31 / 2$ & Normal & Abnormal \\
\hline Normal & 56 & 5 \\
Abnormal & 11 & 8
\end{tabular}

C. Screening by cycloplegic refraction Last known vision

\begin{tabular}{lccc}
\cline { 2 - 4 } Refraction at $31 / 2$ & Normal & Abnormal & Total \\
\hline Normal & 1323 & 20 & 1343 \\
Abnormal & 84 & 80 & 164 \\
Total & 1407 & 100 & 1507 \\
\hline
\end{tabular}

${ }^{*}$ Forty-one with normal refraction and uncertain vision were not followed up.

children $43 \%$ apparently had normal vision at $31 / 2$ years, and they are therefore 'false negatives' of vision screening. The remaining $57 \%$ either did not attend at $3 \frac{1}{2}$ years or were not known to be living in the district at that time.

The results of screening for visual acuity plus a cover test are shown in Table 2A. Two-thirds of the 91 children who were recorded as having abnormal vision actually had a visual defect, but in the case of an almost equal number of children ( 80 or $5.3 \%$ of those who attended), the visual acuity was uncertain or could not be recorded. Refraction helped in the assessment of these children (Table 2B). There were 30 'false positives' of vision screening, but 24 of these had a normal refraction at $3 \frac{1}{2} 2$ years.
Table 3 Results of test for stereoacuity

\begin{tabular}{lll}
\hline & \multicolumn{2}{l}{ Number of children } \\
\cline { 2 - 3 } Stereoacuity & Normal vision & Abnormal vision \\
\hline Normal & 397 & 8 \\
Abnormal & 28 & 4 \\
Impossible & 94 & 4 \\
Not recorded & 16 & 8 \\
\hline
\end{tabular}

Table 4 Results of treating those children identified as having defective vision at age $3^{1 / 2}$ or following uncertain vision at $31 / 2$

\begin{tabular}{|c|c|c|c|c|c|c|c|c|c|}
\hline & \multicolumn{9}{|c|}{ Last known visual acuity } \\
\hline & $6 / 5$ & $6 / 6$ & $6 / 9$ & $6 / 12$ & $6 / 18$ & $6 / 24$ & $6 / 36$ & $6 / 60$ & $<6 / 60$ \\
\hline $\begin{array}{l}\text { Spectacles only } \\
\text { Spectacles }+\end{array}$ & 4 & 21 & 13 & 4 & 4 & - & $1^{*}$ & - & - \\
\hline occlusion & 1 & 2 & 4 & 3 & 4 & 1 & - & 1 & - \\
\hline No treatment & 2 & 4 & 1 & 2 & 1 & - & - & - & - \\
\hline
\end{tabular}

${ }^{*}$ Occlusion declined.

The results of screening by refraction alone are shown in Table 2C. Approximately half of those with an abnormal refraction had abnormal vision, but $20 \%$ of those with abnormal vision had a normal refraction. A squint should have been identified in most of these, but it is not always easy to be sure in practice if a small squint is present. The stereoacuity test proved too unreliable, and $22 \%$ of the children either would not attempt the test or obviously guessed (Table 3).

Children identified at $31 / 2$ years as having abnormal vision were followed up, and most received treatment. The last known acuities of these children are recorded in Table 4. Uncertainty about what an individual child's visual acuity really was made it difficult to decide whether a child of this age had amblyopia requiring occlusion, but when occlusion was given there was only a modest improvement in acuity (Fig. 1). Knowledge of the refraction at age 1 year helped to decide whether amblyopia was likely,

Table 5 Last known acuity of children born 1975-8 identified as having abnormal vision as a result of screening at 31/2 and their refraction at age 1 year

\begin{tabular}{|c|c|c|c|c|c|c|c|}
\hline \multirow{2}{*}{$\begin{array}{l}\text { Meridional refraction } \\
\text { at age } 1 \text { year }\end{array}$} & \multicolumn{7}{|c|}{ Visual acuity } \\
\hline & $6 / 6$ & $6 / 9$ & $6 / 12$ & $6 / 18$ & $6 / 24$ & $6 / 36$ & $6 / 60$ \\
\hline+3.50 D or more & $1(1)$ & $4(2)$ & $2(1)$ & $3(2)$ & $1(1)$ & 1 & $1(1)$ \\
\hline$<+3.50 \mathrm{D}$ & $15(1)$ & $10(2)$ & 1 & 1 & - & - & - \\
\hline Unknown & 2 & 3 & $4(2)$ & $1(1)$ & - & - & - \\
\hline
\end{tabular}

Figures in brackets indicate number of children who had occlusion.

This table illustrates how knowledge of the refraction at age 1 year could help to predict eventual amblyopia after treatment. If a child had had $<+3.50 \mathrm{D}$ meridional hypermetropia at age 1 year, he/she had a much better chance of achieving normal acuity without occlusion than a child who had $+3 \cdot 50$ or more $D$ at 1 year would achieve even after occlusion. 


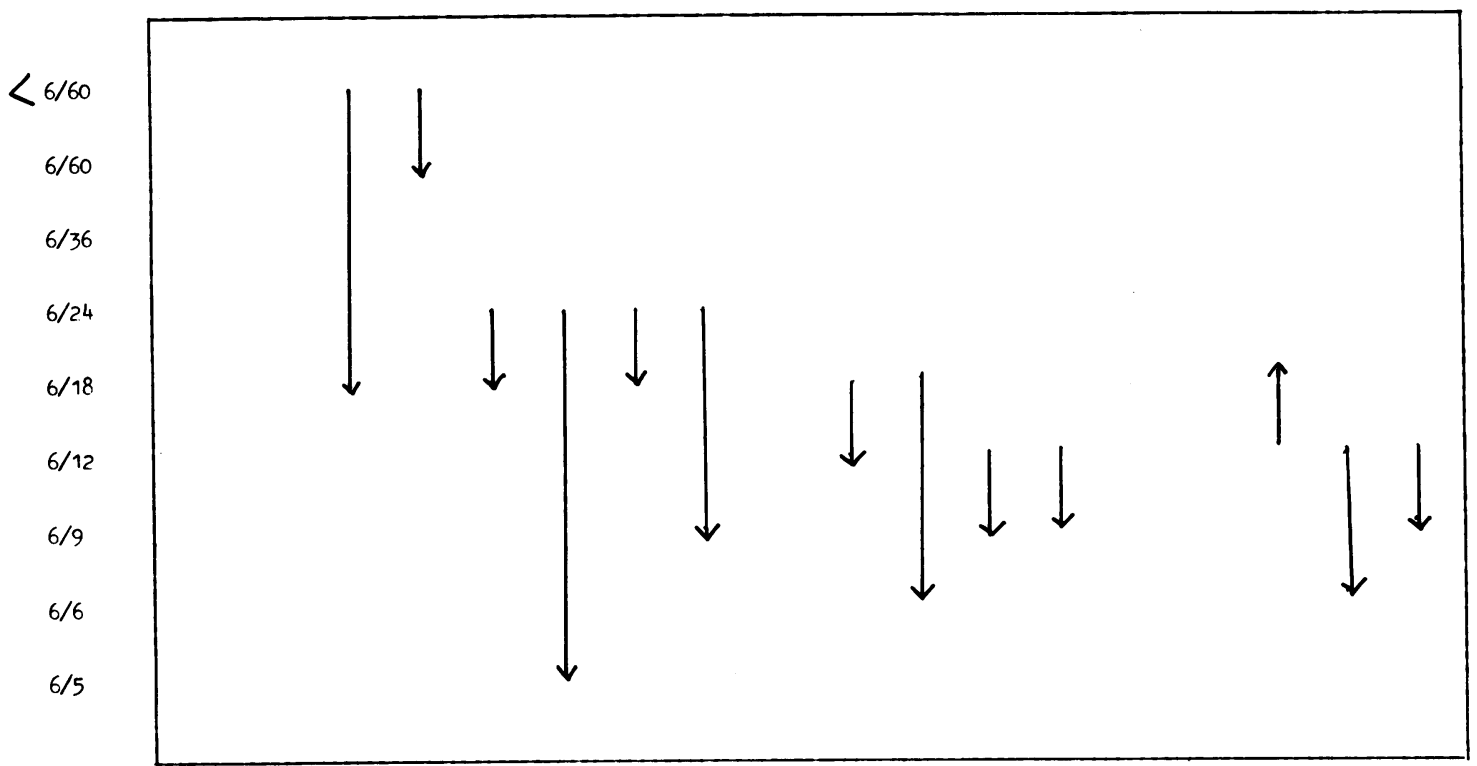

Fig.1 Effect of occlusion in individual children identified as having reduced acuity at age $31 / 2$. Arrows indicate the direction of change in acuity for each child from $31 / 2$ years of age to most recent testing.

and Table 5 shows that abnormal hypermetropia at age 1 year was more likely to be associated with genuinely defective acuity. There was a similar link with infantile hypermetropia in the case of children who presented (with squint) before the age of $3 \frac{1}{2}$ years (Table 6).

Table 7 shows, for all the children in the population sample identified as having abnormal vision, the last known level of acuity irrespective of whether treatment was given. It is important to note that nine of the 10 children left with a severe defect of acuity $(6 / 60$ or less) had presented before age $3 \frac{1}{2}$ years, that is, prior to screening.

\section{Discussion}

There has not yet been time for the final picture of the visual characteristics of these children, particularly the younger ones born in 1978 , to become clear. However, our experience so far prompts some comment on the problems and benefits of early screening at $3 \frac{1}{2}$ years. Screening at this age does detect a considerable proportion ( $41 \%$ ) of children's visual defects, but it must be followed by additional case finding if all abnormalities are to be detected.

The test for stereoacuity proved to be impracticable for many children at this age, and we do not recommend its use for screening. Neither of the other two tests, namely, (1) for visual acuity and/or squint, or (2) for abnormal refractions, was perfect. The following observations are made on the assumption that the first of these methods is the one most likely to be used by non-medical personnel.

(1) Responses of individual children to the test of visual acuity were variable and often uncertain. Refraction proved helpful in distinguishing those

Table 6 Last known acuity of children born 1975-8 who presented before 31/2 and their refraction at age 1 year

\begin{tabular}{|c|c|c|c|c|c|c|c|c|}
\hline \multirow{2}{*}{$\begin{array}{l}\text { Meridional refraction } \\
\text { at age } 1 \text { year }\end{array}$} & \multicolumn{8}{|c|}{ Visual acuity } \\
\hline & $6 / 6$ & $6 / 9$ & $6 / 12$ & $6 / 18$ & $6 / 24$ & $6 / 36$ & $6 / 60$ & $?$ \\
\hline $\begin{array}{c}+3.50 \mathrm{D} \text { or more } \\
\text { or }>-4.00 \mathrm{D}\end{array}$ & - & $1(1)$ & $2(2)$ & - & - & - & $3(2)$ & - \\
\hline$<+3.50 \mathrm{D}$ & $7(2)$ & $3(2)$ & $3(3)$ & - & - & - & - & 1 \\
\hline Unknown & 2 & 3 & $2(2)$ & $1(1)$ & - & $1^{*}(1)$ & $1(1)$ & 1 \\
\hline
\end{tabular}

Figures in brackets indicate number of children who had occlusion.

*This child had +6-25 D at age 16 months. He has also had occlusion.

This table illustrates how the presence of ametropia at age 1 year altered the prognosis for treating children who presented before $31 / 2$ with abnormal vision (i.e., squint). 
Table 7 Age of presentation of children identified as having visual defects and their last known acuity (irrespective of whether treatment was actually given)

\begin{tabular}{llllllllll}
\hline \multicolumn{1}{c}{ Visual acuity } \\
\cline { 2 - 8 } & $6 / 5$ & $6 / 6$ & $6 / 9$ & $6 / 12$ & $6 / 18$ & $6 / 24$ & $6 / 36$ & $6 / 60$ & Unknown \\
\hline Before 31/2 & - & 11 & 10 & 7 & 4 & 1 & 1 & 9 & 4 \\
At age 31/2* & 7 & 27 & 18 & 9 & 9 & 1 & 1 & 1 & 1 \\
After 31/2 $\dagger$ & 2 & 17 & 23 & 5 & 5 & - & 1 & - & 7 \\
\hline
\end{tabular}

*Includes those with uncertain vision at $31 \frac{1}{2}$ and who were subsequently treated.

†Includes false normals at $3 \frac{1}{2}$

This table shows that most of the children in the total population sample who ended up, after all treatment, with the worst vision had presented (with squint, to the hospital clinic) before $31 / 2$.

with normal vision from those with abnormal vision requiring treatment.

(2) $33 \%$ of the children in this population sample who had a visual defect were 'missed' by screening at $31 / 2.14 \cdot 4 \%$ of the total with visual defects gave a 'false normal' response to the test; the remainder did not attend for screening, some because they were not known to be living in the district at that time. This is an administrative problem which could to some extent be overcome.

(3) $26 \%$ of the total number of children with a visual defect had presented before age $3 \frac{1}{2} 2$ (Table 1 ). In this sample (Table 7) nine of the 10 children who ended up with $6 / 60$ or less were in this group, and, so far as they were concerned, screening at age $3 \frac{1}{2}$ was irrelevant.

Consideration of the results of treating children identified as abnormal by a screening procedure is an essential part of the assessment of the value of that screening procedure. Variable responses to visual acuity tests at this age made it difficult to differentiate children with amblyopia requiring occlusion from others with 'blurred vision' due to uncorrected errors of refraction. Most of the children achieved normal corrected acuity (Table 4), but the outcome of occlusion at this age was not very encouraging, only three of 16 achieving $6 / 6$ (Fig. 1). These indifferent results may reflect uncertainty about who should have had occlusion and for how long. We eventually realised that the prognosis for treatment depended to some extent on whether a child had abnormal hypermetropia (+3.50 D or more in any one meridian) at age 1 year. This is illustrated for the children born between 1975 and 1978 (Table 5). Those who had abnormal refractions at 1 year often did not get and retain normal acuity, even with occlusion.

It is worth noting that the majority of children who presented before $31 / 2$ (Table 6 ) also achieved reasonable acuity. Two-thirds of these were known to be not abnormally hypermetropic at age 1 year, but four of the five who ended up with $6 / 36$ vision or less were abnormally hypermetropic at 1 year. This suggests that whether or not a child ends up with severe amblyopia after all treatment may be primarily determined by whether or not he had abnormal hypermetropia or (rarely) myopia at 1 year, and that this may be more important than the age at which defective vision is identified.

Children with abnormal refractions likely to lead to severe amblyopia can be identified in $3.7 \%$ of the population at age 1 year, ${ }^{9}$ but unfortunately optical correction from that age does not alter the prognosis. ${ }^{10}$ If we are to tackle the problem of severe amblyopia, these are the children who primarily require our attention, but their problem has to be approached before age $3 \frac{1}{2}$.

The case for preschool screening at $3 \frac{1}{2}$ for amblyopia rests on whether those children with mildly defective acuity corrected with glasses at $3 \frac{1}{2}$ would develop irreversible amblyopia, or their condition deteriorate in some other way after that age if they had not been treated. It will be extremely difficult to prove this, since a large number of children would need to be screened to identify a relatively small number with clearly defined visual defects. Some of these would then have to be given immediate treatment and others delayed treatment. If such a study were to be mounted, we think that screening for abnormal refractions would provide the quickest means of identifying cases, perhaps with the use of one of the recently developed photographic methods. ${ }^{.12}$

\section{CONCLUSIONS}

The relatively small number of children reported here makes it difficult to establish conclusively that the incidence or severity of amblyopia is reduced by preschool screening at $3 \frac{1}{2}$ years of age, since the overall incidence in any population is comparatively small. However, amblyopia detected at this age cannot often be eliminated. Of all visual defects apart from puberty-onset myopia fewer than half were detected through screening at $3 \frac{1}{2}$, and most of the children who ended up with the worst acuity even after treatment had presented before $3 \frac{1}{2}$. Only $70-75 \%$ of the population available attended screening, suggesting that it would be administratively problematic to organise screening of a relatively noncaptive population of this age. Screening at age 1 year, however, achieved a $10 \%$ higher response rate, and the use of refraction at this age may provide a better means of identifying those children likely to have the most severe amblyopia. This study emphasises the need for further critical assessment before any move is made to introduce screening of $31 / 2$-year-old children on a national basis. 
We thank all the general practitioners in Kettering and Rushden for allowing us to use their premises for the purpose of screening and thus giving us the possibility of studying their patients. We thank all the appropriate health visitors who arranged the details of the screening in the first place. We also thank Mrs L A Neale and Mrs D Maddams for secretarial assistance throughout.

\section{References}

1 Committee on child health services. Fit for the future. Cmnd. 6684. London: HMSO, 1968.

2 Ingram RM. The problem of screening children for visual defects. BrJ Ophthalmol 1977; 61: 4-7.

3 Friendly DS. Pre-school visual acuity screening tests. Trans Am Ophthalmol Soc 1978; 76: 383-480.

4 Hall SM, Pugh AG, Hall DMB. Vision screening in the under 5's. Br Med J 1982; ii: 1096-8.

5 Sackett DL, Holland WW. Controversy in the detection of disease. Lancet 1975; ii: 357-9.
6 Wilson JMG, Jungner G. Principles and practices of screening for disease. Public Health Paper No. 34. Geneva: WHO, 1968.

7 Reinecke RD, Simons K. A new stereoscopic test for amblyopia screening. Am J Ophthalmol 1974; 78: 714-21.

8 Ingram RM. Refraction as a basis for screening children for squint and amblyopia. Br J Ophthalmol 1977; 61: 8-15.

9 Ingram RM, Walker C, Wilson JM, Arnold PE, Dally S. Prediction of amblyopia and squint by means of refraction at age 1 year. Br J Ophthalmol 1986; 70: 12-15.

10 Ingram RM, Walker C, Wilson JM, Arnold PE, Lucas J, Dally S. A first attempt to prevent amblyopia and squint by spectacle correction of abnormal refractions from age 1 year. $\mathrm{Br} J$ Ophthalmol 1985; 69: 851-3.

11 Atkinson J, Braddick OJ, Durden K, Watson PG, Atkinson S. Screening for refractive errors in 6-9 month old infants by photorefraction. Br J Ophthalmol 1984; 68: 105-12.

12 Sjostrand D, Abrahamsson M, Fabian G, Wenhall O. Photorefraction: a useful tool to detect refraction errors. Acta Ophthalmol (Kbh) 1982; 157 (suppl): 46-52.

Accepted for publication 24 May 1985. 